\title{
National Ignition Facility Sub-System Design Requirements Integrated Safety Systems SSDR 1.5.4
}

\author{
R. Reed
}

P. VanArsdall

E. Bliss

| September 3, 1996

This is an informal report intended primarily for internal or limited external diatribution. The opinions and conclusions stated are those of the author and may or may not be those of the Laboratory.

Work performed under the auppices of the U.S. Department of Energy by the Lawrence Livermore National Laboratory under Contract W-7405-Eng-48. 


\section{DISCLAIMER}

This document was prepared as an account of work sponsored by an agency of the United States Government. Neither the United States Government nor the University of California nor any of their employees, makes any warranty, express or implied, or assumes any legal liability or responsibility for the accuracy, completeness, or usefulness of any information, apparatus, product, or process disclosed, or represents that its use would not infringe privately owned rights. Reference herein to any specific commercial product, process, or service by trade name, trademark, manufacturer, or otherwise, does not necessarily constitute or imply its endorsement, recommendation, or favoring by the United States Government or the University of California. The views and opinions of authors expressed herein do not necessarily state or reflect those of the United States Government or the University of California, and shall not be used for advertising or product endorsement purposes.

This report has been reproduced directly from the best available copy.

Available to DOE and DOE contractors from the Office of Scientific and Technical Information

P.O. Box 62, Oak Ridge, TN 37831

Prices available from (615) 576-8401, FTS 626-8401

Available to the public from the

National Technical Information Service

U.S. Department of Commerce

5285 Port Royal Rd.,

Springfield, VA 22161 


\title{
National Ignition Facility
}

\section{Sub-System Design Requirements}

\author{
Integrated Safety Systems \\ SSDR 1.5.4
}

Revision 2

3 September 1996

Prepared by:

R. Reed, Integrated Safety Systems Team Leader

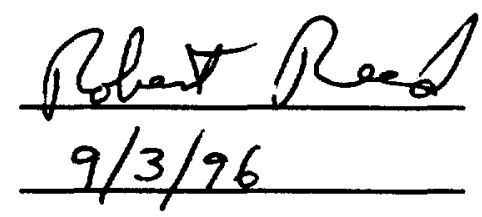

P. VanArsdall, Integrated Computer Controls

Date

Lead Engineer

E. Bliss, System Controls System Engineer

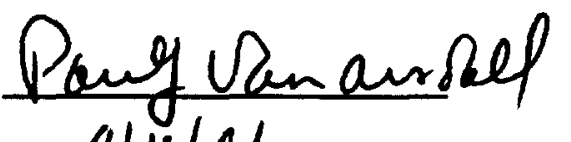

Special Equipment Engineering Approval:

R. Sawicki, NIF Associate Project Engineer

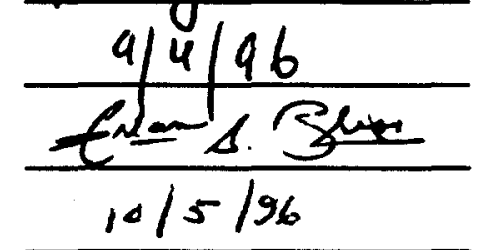

Date

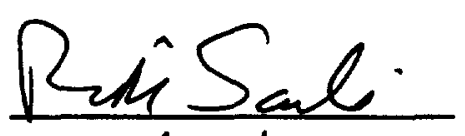
1.121146

Engineering Review Board Approval:

S. Kumpan, NIF Project Engineer

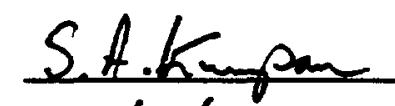

Approval Date

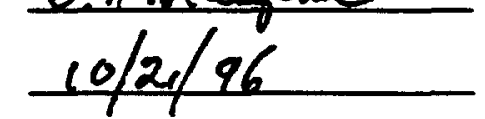




\section{Table of Contents}

Paragraph Title

1.0

2.0

2.1

2.2

2.3

2.4

2.5

2.6

3.0

3.1.1

3.1 .3

3.1 .4

3.1 .5

3.2 .00

3.2.01

3.2.02

3.2 .03

3.2 .04

3.2 .05

3.2.06

3.2.07

3.2 .08

3.2 .09

3.2.10

3.2.11

3.2.12

3.2 .13

3.2.14

3.2.15

3.2 .16

3.2.16.1

3.2.16.2

3.2.16.3

3.2.16.4

3.2.16.5

3.2.17

3.2 .18

3.2.18.1

3.2.18.2

3.2.18.3

3.2.18.4

3.2 .19

3.2 .20

3.2 .21

3.4

3.4 .1

3.4 .2

6.0
Scope

Applicable Documents

Applicable NIF Project Documents

Applicable US Government Orders and Standards

Applicable National Consensus Codes and Standards

Applicable LLNL Standards

Supporting Documentation Standards

References

Requirements and Verification

System Description

Conceptual Integrated Safety System (ISS) Block Diagram

System Interfaces

Integrated Safety Systems, Major Subsystems - WBS 1.5.4

Functional Requirements

Quality Level Requirements

Monitor Safety Protective Devices

Determine Permissives

Personnel Access

Display of Hazard Levels/Changes

Waming Announcement

Personnel Sweep

CRASH Boxes

Shutters, Door Bolts and Permissives

Segmented and Concurrent Operation

Area Hazard Table

Interface to Ionizing Radiation Hazard Monitors

Hardware Interface to Building

FEP Software Requirement Specification

PLC Software Requirement Specification

Lifetime, Replaceability and RAM

Lifetime

Replaceability

Reliability

Availability

Maintainability

Recovery From Abnormal Event

Environmental/EMI Requirements

Environmental, Temperature/Humidity

Environmental/Plenum Approved/CL2 Cables

Environmental, EMI Requirements

Environmental, Ionizing Radiation

Optical Communication Safety

Human Factors

Documentation and Records

Logistics

Spares

Maintenance

Revision Record 


\subsection{Scope}

This System Design Requirement document establishes the performance, design, development, and test requirements for the Integrated Safety System, WBS 1.5.4 which is part of the NIF Integrated Computer Control System (ICCS). This document responds directly to the requirements detailed in ICCS (WBS 1.5) which is the document directly above.

\subsection{Applicable Documents}

This section lists DOE orders, codes, and standards which are applicable to the NIF Integrated Computer Control System. The applicable portions of these documents apply. Applicable LLNL standards are being considered contingent upon the decision of final site selection.

\subsection{Applicable NIF Project Documents}

National Ignition Facility Functional Requirements and Primary Criteria, Revision 1.4, Mar 96.

\subsection{Applicable US Government Orders and Standards}

US. Government DOE General Orders:

DOE 5700.6C - Quality Assurance (flowdown from FRPC and SDR4)

Other US. Government Regulations:

10 CFR835 Occupational Radiation Protection (flowdown from FRPC and SDR4)

\subsection{Applicable National Consensus Codes and Standards}

\section{General Standards:}

Do not apply to this document.

Safety Standards:

National Fire Protection Association (NFPA)-70 National Electrical Code

National Fire Protection Association (NFPA)-101 Life Safety Code

29 CFR 1910 Occupational Safety and Health Act (OSHA)

ANSI Z-136.1 (1993) and ANSI Z-136.2 (1988) Laser Safety Standards

Software and Electronic Standards:

NEMA ICS6 Enclosures for Industrial Control Systems

UL Standards, Underwriters Laboratory, Inc.

Ethernet

FDDI

RS-232C

RS-485

IEEE-488

VMEbus

Ada 83

Ada 95

$\mathrm{X} 11$

OSF/Motif

Postscript

POSIX

TCPIP

OSIISO

OSF/DCE

OSF/DME
IEEE-802.3 Local Area Network for Data Communications

Fiber Distributed Data Interface, ANSI Standard X3.139-1987

EIA Serial interface standard

EIA Multi-drop serial interface standard

Standard Digital Interface for Programmable Instrumentation, ANSI/IEEE Std 488.1-1987 and ANSI/IEEE Std 488.2-1987

IEEE-1014

ANSIMIL-STD-1815A-1983, programming language

International Standard ANSI/ISO/IEC-8652:1995, January 1995

$\mathrm{X}$ Window System, Version 11 , windows graphics standard, MIT X Consortium

Motif graphical user interface, Open Systems Foundation

Text and graphics printing language, Adobe Systems Inc.

IEEE-1003 portable application programming environment

Protocol stack for network communications

Open Systems Interconnect protocol stack for network communications

Distributed Computing Environment, Open Systems Foundation

Distributed Management Environment, Open Systems Foundation 


\subsection{Applicable LLNL Standards}

General:

LLNL M-010, March 1989, "Health and Safety Manual"

\subsection{Supporting Documentation Standards}

Instrument Society of America, ISA-S5.1, Instrumentation Symbols and Identification

Instrument Society of America, ISA-S5.5, Graphics Symbols for Process Displays

ANSI/IEEE Std 730.1-1989, IEEE Standard for Software Quality Assurance Plans

ANSI/IEEE Std 830-1984, IEEE Guide for Software Requirements Specification

ANSI/IEEE Std 1016-1987, IEEE Recommended Practice for Software Design Descriptions

ANSI/IEEE Std 828-1983, IEEE Standard for Software Configuration Management Plans

ANSI/IEEE Std 982.1-1988, IEEE Standard Dictionary for Measures to Produce Reliable Software

ANSI/IEEE Std 982.2-1988, IEEE Guide for the Use of IEEE Standard Dictionary of Measures

Produce Reliable Software

ANSI/IEEE Std 1063-1987, IEEE Standard for Software User Documentation

\subsection{References}

NIF-LLNL-95-044/L-15958-2, National Ignition Facility Quality Assurance Program Plan, September 1995

NIF-LLNL-94-017/L-15958-5, NIF Ancillary Software Quality Assurance Plan, January 12, 1994

NIF-LLNL-93058, National Ignition Facility Functional Requirements and Primary Criteria

\subsection{Requirements and Verification}

\subsubsection{System Description}

The safety interlock system is responsible for monitoring various interlock conditions on doors, hatches, shutters, and other equipment. Permissive signals are supplied to the power conditioning system and/or laser shutters when operations are determined to be safe. The design is fail-safe and is accomplished via programmable logic controllers (PLC) connected via fiber optic links to remote V/O units located in equipment areas. Software development and operator controls are provided as part of the PLC system

The access control system tracks entry and egress through monitored doors by sensing special badges carried by all personnel. All movement into or out of the equipment bays is recorded and printed to a transaction $\log$. A permissive from this system is forwarded to the safety interlock system to help ensure no personnel are present in the bays prior to a laser shot.

The T-1 Abort System monitors positions of key components in the Hartman sensor of each beam, and aborts a system shot during the final second if these components have not reached their proper shot configuration. Portions of the Abort system are implemented by the Integrated Timing System. 


\subsubsection{Conceptual Integrated Safety System (ISS) Block Diagram}

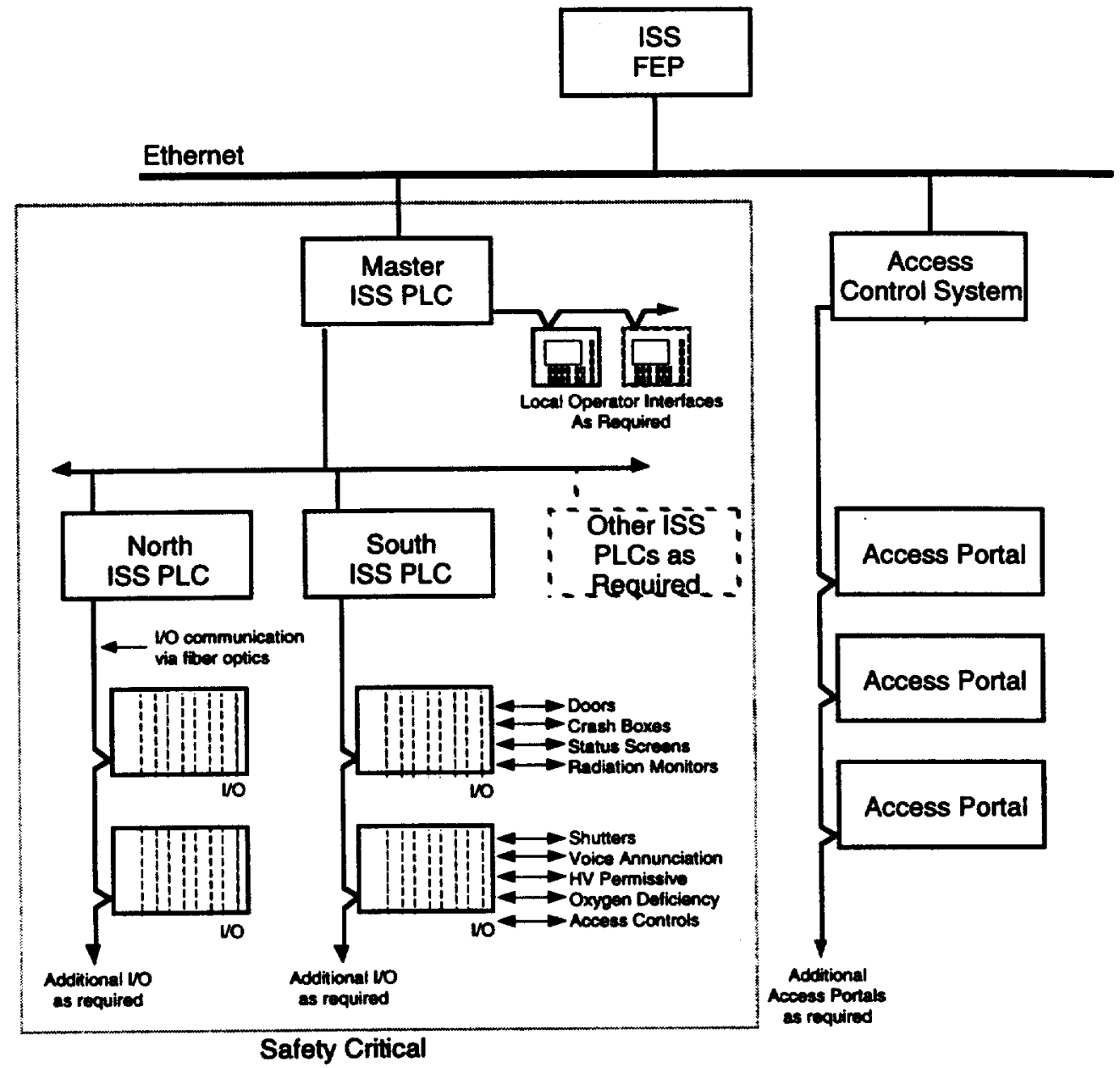

\subsubsection{System Interfaces}

The Integrated Safety System has interfaces with the following WBS areas:

WBS 1.2.2 Public Address, Door Switch, Alarm and Crash Box Wiring

WBS 1.5.1 Control Room Consoles (key switches, Crash Buttons)

WBS 1.5.2 Supervisory Software (status)

WBS 1.3.1 OPG (status)

WBS 1.7 Beam Diagnostics, Wavefront Correction (Covers, Light Sources)

WBS 1.7.1 Alignment Systems (shutters, solenoids)

WBS 1.8.5 Target Area Radiation Monitors (status)

WBS 1.5.5 Automatic Alignment (permissives)

WBS 1.3.4 Amplifier Power Conditioning (permissives)

WBS 1.5.1 Local Area Network (communications)

WBS 1.5.3 Integrated Timing System (T-1 Abort signal) 


\subsubsection{Integrated Safety Systems, Major Subsystems - WBS 1.5.4}

Consists of WBSs:

1.5.4.1 Safety Interlocks

1.5.4.2 Access Controls

1.5.4.3 T-1 Abort System

\subsubsection{Functional Requirements}

The safety interlock system shall detect and mitigate safety hazards due to laser light and high voltage in the capacitor bays, laser- and target-areas. Permissives to hazardous equipment shall only be given when it is safe for the equipment to operate. The hazard level shall be reported audibly and visually to personnel in all affected areas of the facility. Sufficient time shall be given for personnel to leave the affected area or to operate a nearby CRASH button. CRASH buttons effectively break the interlock chain and remove all permissive signals from interlocked hardware.

The safety interlock system shall be designed to provide a safe operating environment for all personnel. Machine interlock functions are designed into appropriate subsystems to either protect high valued equipment within the facility or to prevent loss of important experimental data. These safety and protection systems generally apply to safety shutter systems, power supply systems, the alignment system, vacuum systems, and others. These systems shall be designed, tested and installed in accordance with the applicable codes and standards as specified in para. $2.3,2.4,2.5$ above.

Safety interlocks shall:

- open and close safety shutters (permissive or actual actuation?)

- provide and control all LTAB warning-light panels

- determine hazard levels

Uncontrolled Entry

- No hazard, open entry

Controlled Entry: (laser light present)

- 1 omega light present

- 2 omega light present

- 3 omega light present (UV)

No Entry: (Area Evacuated)

- Shot in progress or imminent

- High Voltage present

- Oxygen depletion condition present

- High ionizing radiation present (from monitors in WBS 1.8.5)

- provide and control area audible alarms (e.g. chimes or klaxon)

- provide voice annunciation of hazard level giving sufficient time to evacuate area or activate crash box

- determine and provide permissive signals to power conditioning

- lock and unlock area entrance doors

- monitor (and respond) to access control system status

- monitor SAFE/OPERATE key switches and CRASH boxes

- monitor door switches and beam shutter positions

- provide software development environment for system

- provide operator control and status screens

- be modular allowing support of partial system operation during startup or maintenance

- allow administrative bypass of single point failures

- require operator action to re-enable systems after an interlock dump

- be integrated with appropriate OSPs, FSPs and Administrative Procedures that will require personnel sweeps and surveillance systems 
In addition, for off-normal or emergency operations, the safety interlocks shall:

- de-energize devices to safe state upon loss of AC power (fail-safe)

- allow unrestricted egress from facility

- close all shutters and reinitialize to a safe state upon reapplication of $\mathrm{AC}$ power

Access control system shall:

- monitor entry and egress of all personnel through major access points

- $\quad \log$ all monitored access point transactions

- provide permissive to interlock system when areas are clear of personnel

- display summary status

- identify and approve personnel access by name and training records

- provide software development environment for specialized computer equipment

- be modular allowing support of partial system operation during startup or maintenance

The T-1 Abort System shall:

- Monitor positions of selected components in the Hartman sensors of each beam for proper position before allowing a system shot.

- Abort a system shot, or issue abort command to the Integrated Timing System if the selected components in active beams do not reach their shot configuration positions during the final second prior to a shot.

- Be modular allowing support of partial system operation during startup or maintenance.

\subsubsection{Quality Level Requirements}

The Safety System shall adhere to the following Quality Level specifications. Reference for QA Level is the NIF QA Plan as stated in paragraph 2.6 of this document.
WBS 1.5.4.1 Safety Interlocks
WBS 1.5.4.2 Access Controls
Q-Level 2
WBS
1.5.4.2 Access Controls
1.5.4 1 Abort System
Q-Level 3
Q-Level 3

\subsubsection{Monitor Safety Protective Devices}

The Integrated Safety System (ISS) shall continuously monitor all appropriate protective devices in the safety interlock control point table. It shall log and display all appropriate data and status. 


\begin{tabular}{|l|l|c|l|}
\hline \multicolumn{2}{|c|}{ NIF Safety Interlock Control Point Table } & & \\
\hline Control Point & \multicolumn{1}{|c|}{ Function/Description } & Qty(est) & Supplier WBS \\
\hline Shutters & Front End Output & 192 & 1.3 .1 \\
\hline & PAM Output & 192 & 1.3 .1 \\
\hline & Laser Bay Alignment lasers & 8 & 1.7 .1 \\
\hline & Laser Bay to Switchyard & 192 & 1.4 .1 \\
\hline & Switchyard to Target Bay & 192 & 1.4 .1 \\
\hline Doors & Unlock Door Solenoid & 12 & 1.5 .4 .2 \\
\hline Status & Status Indicators from Power Conditioning & 4 & 1.3 .4 \\
\hline & Status of Viewing Gallery & 1 & 1.5 .5 .1 \\
\hline Permissives & Permissives to Power Conditioning & 4 & 1.3 .12 \\
\hline & Permissive to PAM & 192 & 1.4 .1 \\
\hline & Permissive to Pockels Cell & 4 & 1.3 .3 \\
\hline & Courtesy Permissive to Auto Alignment System & 4 & 1.5 .5 .1 \\
\hline Alarms & Hazard Area Audio Alarms & 11 & 1.5 .4 .1 \\
\hline & Access Warning Panel & 12 & 1.5 .4 .1 \\
\hline & Laser Status Warning Panels & 32 & 1.5 .4 .1 \\
\hline & Audio Annunciator & 11 & 1.5 .4 .1 \\
\hline Crash Panels & Safe/Operate Box Push Button and Key Sw. & 100 & 1.5 .4 .1 \\
\hline Displays & Safe/Operate Lights & 50 & 1.5 .4 .1 \\
\hline Key Interlocks & System Bypass Key Operations & 10 & 1.5 .1 .4 \\
\hline
\end{tabular}

\subsubsection{Determine Permissives}

The Integrated Safety System (ISS) shall determine permissives to prevent unsafe operation. Worst case response time shall be 500 milliseconds.

Quantity of independent permissives is derived from operational segmentation requirements.

\subsubsection{Personnel Access}

The Integrated Safety System (ISS) shall control personnel access via door bolt controls and badge readers. It shall include support for an administrative access database and the tools to modify (add and delete personnel and accessible areas) the database on-line.

\subsubsection{Display of Hazard Levels/Changes}

The Integrated Safety System (ISS) shall display hazard levels and level changes on walls and other appropriate locations. There shall be both visual and audible indicators to notify personnel of levels and changes in hazard levels.

Hazard status displays are located on system access control panels at the entrances to the facility and on the interior walls at locations that can be seen from most places within the facility. These displays change with the status of the safety interlock system and indicate the protective measures that shall be taken by personnel in the facility.

When eye hazard conditions exist, the interlock on any access door (not locked for security access) may be temporarily bypassed to allow entry into the facility without shutting off the laser. The bypass for a door is activated by acknowledging the hazard level on the access control panel and presenting a NIF access control badge to the badge reader. 


\section{HAZARD STATUS DISPLAY TABLE}

\begin{tabular}{|c|c|c|}
\hline $\begin{array}{l}\text { Sign } \\
\text { "Safe" and "Safe to Enter" }\end{array}$ & $\begin{array}{l}\text { Color } \\
\text { Green }\end{array}$ & $\begin{array}{l}\text { Reference } \\
\text { When this sign is lit, no unusual hazard exists in the area. Power } \\
\text { supplies are off and laser glasses are not required. Be aware of local } \\
\text { signs and warning lights that may indicate the need for eye protection } \\
\text { within specified work areas. }\end{array}$ \\
\hline "Caution, Carry Goggles" & Yellow & $\begin{array}{l}\text { When this sign is lit, the interlock chain is completed and a laser } \\
\text { power supply is on. All personnel entering the area are expected to } \\
\text { have appropriate eye protection in their possession. An announcemen } \\
\text { will describe a hazard level change } 30 \text { seconds before it occurs. }\end{array}$ \\
\hline "1 $\omega$ Low Level Beams" & Yellow & $\begin{array}{l}\text { When this sign is lit, a } 1 \omega \text { (omega) beam whose intensity is below } \\
0.1 \text { MPE (Maximum Permissible Exposure) for direct ocular } \\
\text { exposure is being propagated in the laser beam lines. In this case, no } \\
\text { eye protection is required for personnel not working directly in the } \\
\text { beam. }\end{array}$ \\
\hline
\end{tabular}

" $2 \omega, 3 \omega$, Low Level Beams" Yellow

When this sign is lit, a $2 \omega$ or $3 \omega$ beam (whose intensity is below 0.1 MPE for direct ocular exposure) is being propagated in the laser beamline. In this case, no eye protection is required for personnel not working directly in the beam.

"Wear $1 \omega$ Goggles" $\quad$ Yellow

When this sign is lit, the potential for exposure to $1 \omega$ laser light above 0.1 MPE exists in the area. All personnel entering must wear approved $1.053 \mathrm{~nm}$ eye protection.

"Wear 2 $\omega$ Goggles" Yellow

When this sign is lit, the potential for exposure to $2 \omega$ laser light above $0.1 \mathrm{MPE}$ exists in the area. All personnel entering must wear approved $2 \omega$ eye protection.

"Follow UV Procedure"

"High Voltage"

"Radiation Hazard" Magenta Flashing

Yellow
When this sign is lit, potential for exposure to $3 \omega$ laser light above 0.1 MPE exists in the area. All personnel entering must wear approved $3 \omega$ eye protection. Skin protection may also be required for personnel working directly with the beam.

Yellow Flashing In the Laser Bay, this sign indicates that permissives are granted to charge and fire the large amplifiers. This indication will always be coincident with "Extreme Hazard," and no personnel should be present in the Laser Bay.

In the Target Bay, Diagnostic Bay and Switchyard, this sign indicates that a high level of Ionizing Radiation is present. This indicator is coincident with "Extreme Hazard", and no personnel should be present in the area. 
"Oxygen Depletion" Yellow Flashing "Keep Out - Extreme Hazard" Red
and "Extreme Hazard"
When this sign is flashing, oxygen depletion sensors in the area have detected an unacceptably low level of breathable oxygen in the air. Personnel without auxiliary breathing apparatus shall immediately leave the area. (note: gas flow systems shall be shut down to eliminate the source)

When these signs are lit, the interlocks for the laser bay, switchyard, target bay are made up. The capacitor bank interlocks are also made up, and a potential for electrical shock and/or explosion of a component from the failure of a high energy electrical circuit exists in the laser bay and switchyard. A potential also exists for exposure to high power laser light in these areas. Also a potential hazard of oxygen depletion exists. Additionally a hazard due to ionizing radiation exists in the Target Bay, Diagnostic Bay and Switchyard.

When these signs are lit, there is also a loud slowly varying signal from low to high frequency (slow whoop), repeating approximately every 2 seconds.

When these signs are lit, personnel are required to clear the area and viewing galleries.

\subsubsection{Warning Announcement}

The safety interlock system automatically plays an audible warning tape thirty seconds prior to a change in status that allows propagation of a laser beam in the facility. This announcement indicates the eye hazard to be expected. All personnel in the affected areas shall follow the instructions given in the warning, or disable the system by pushing a panic interrupt or run safe button. If the interlock system has been interrupted upon reset, the warning announcement and delay are repeated before the lasers are re-energized. Operators are required to give a verbal waming 60 seconds before initiating a capacitor bank charging sequence. All personnel in the facility are to follow the instructions given in the warning or disable the system by pushing a panic interrupt or run safe button.

\subsubsection{Personnel Sweep}

A personnel sweep shall be made prior to a shot in areas which will contain extreme electrical or optical hazards in accordance with all OSPs and Administrative Procedures. The Access Control system shall be used to check for occupancy of the affected areas. In addition, the system operators will make warning announcements to clear the affected areas during their final shot preparations. This shall be in addition and prior to actuation of automatic audible and visual warnings.

\subsubsection{CRASH Boxes}

The Integrated Safety System (ISS) shall provide crash (run-safe) boxes throughout the hazardous areas of the facility to allow personnel to render the system safe at any time. These boxes shall contain at a minimum:

A crash button;

A status indicator and;

A reset key-switch. 


\subsubsection{Shutters, Door Bolts and Permissives}

Operation of ISS controlled shutters, door bolts and permissives shall follow the table below:
Door Bolts
Loss of power - Open
Shutters
Loss of Permissive - Close
Loss of Power - Close
Loss of Permissive - Close

(Note this does not pose a door egress safety hazard as personnel can always exit from an internal area by use of the door mechanical crash bar or internally operated latch, even if a permissive is not given.)

Loss of power to circuitry supplying permissives to Power Conditioning, PAM, Pockels Cell and Auto Alignment shall remove the permissive and be equivalent of a command the to the safe or deactivated state.

\subsubsection{Segmented and Concurrent Operation}

The Integrated Safety System shall be capable of operating the NIF in a segmented mode with the segments functioning concurrently in different configurations. As an example, a portion of the laser may be under maintenance or construction and the rest of the laser operational. The Integrated Safety System shall support the area under construction with appropriate test sequences, diagnostics and construction debugging tools, while simultaneously supporting shot sequences on the operational segment of the laser.

In general, the ISS shall be capable of operating each of the area of LTAB designated:

$\begin{array}{ll}\text { DB } & \text { Diagnostic Building } \\ \text { SY1 } & \text { Switchyard 1 } \\ \text { SY2 } & \text { Switchyard 2 } \\ \text { TB } & \text { Target Bay } \\ \text { CB1 } & \text { Capacitor Bay 1 } \\ \text { CB2 } & \text { Capacitor Bay 2 } \\ \text { CB3 } & \text { Capacitor Bay 3 } \\ \text { CB4 } & \text { Capacitor Bay 4 } \\ \text { LB1 } & \text { Laser Bay 1 } \\ \text { LB2 } & \text { Laser Bay 2 } \\ \text { MOR } & \text { Master Oscillator Room }\end{array}$

such that each area can be operated independently. Additionally, the ISS shall allow adjacent areas to be combined and operated as a unit, up to and including operating the entire building as a unit supporting full shot operation. 


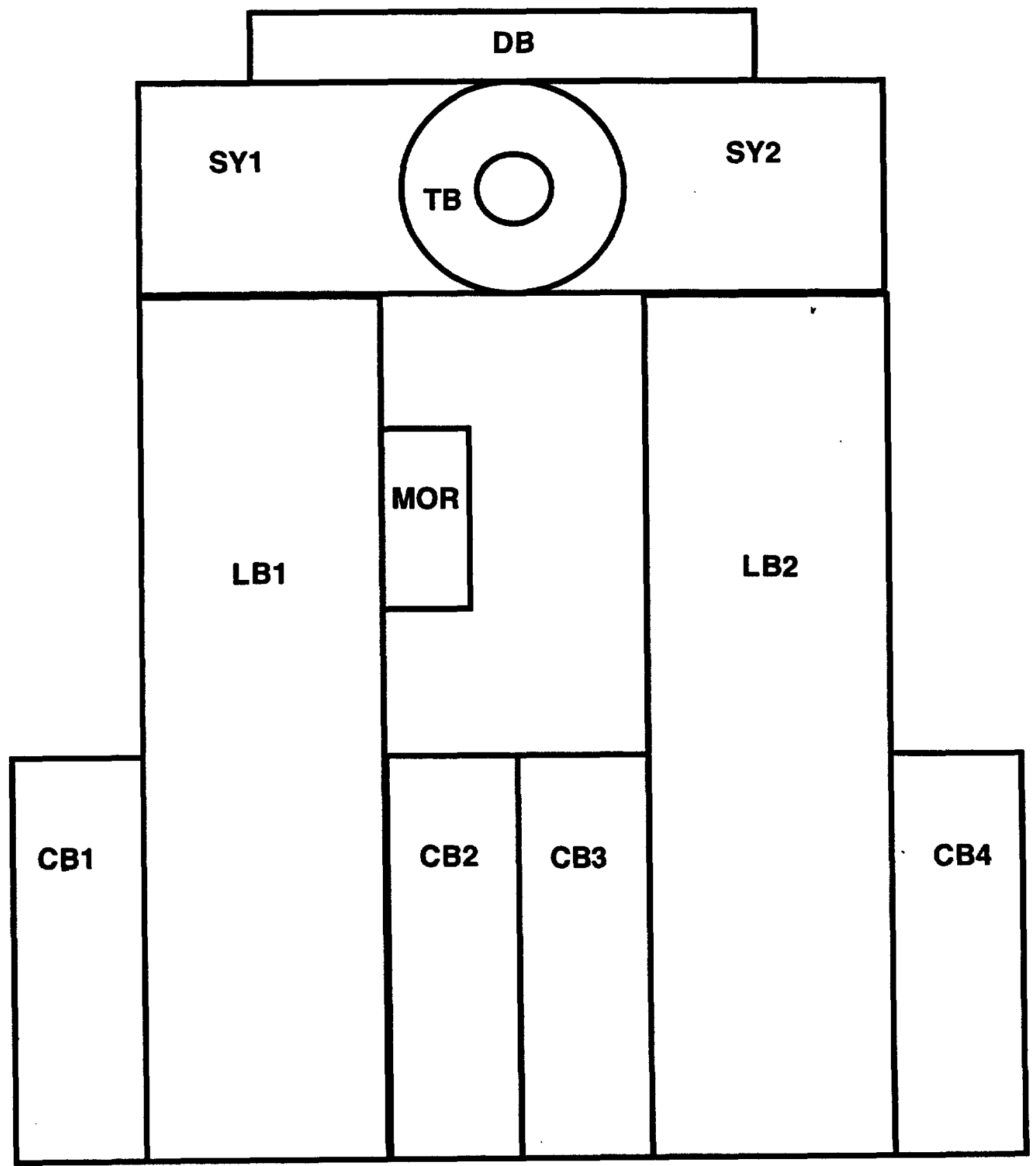




\subsubsection{Area Hazard Table}

This table delineates the potential hazard in each of the areas of the NIF facility.

\begin{tabular}{|c|c|c|c|c|c|c|c|}
\hline \multicolumn{8}{|c|}{ NIF Safety Interlock Area Hazard Table } \\
\hline$\overline{\text { Area }}$ & Low Level & 1 omega & $\overline{2 \text { omega }}$ & 3 omega/UV & $\overline{\overline{H V}}$ & $\overline{\mathrm{Rad}}$ & $\overline{\overline{\mathrm{O}_{2} \mathrm{Dep}}}$ \\
\hline Diagnostic Building & $\bar{x}$ & $\bar{x}$ & & & & $\bar{x}$ & $\bar{x}$ \\
\hline Switchyard 1 & $\bar{X}$ & $\bar{X}$ & & & & $\bar{X}$ & $\bar{X}$ \\
\hline Switchyard 2 & $\bar{X}$ & $\bar{X}$ & & & & $\bar{X}$ & $\bar{X}$ \\
\hline Target Bay & $\bar{X}$ & $\bar{X}$ & $\bar{X}$ & $\bar{X}$ & & $\bar{X}$ & $\bar{X}$ \\
\hline Capacitor Bay 1 & & & & & $\overline{\mathbf{X}}$ & & \\
\hline Capacitor Bay 2 & & & & & $\bar{X}$ & & \\
\hline Capacitor Bay 3 & & & & & $\bar{X}$ & & \\
\hline Capacitor Bay 4 & & & & & $\bar{X}$ & & \\
\hline Laser Bay 1 & $\bar{X}$ & $\bar{x}$ & & & $\bar{X}$ & & $\bar{x}$ \\
\hline Laser Bay 2 & $\overline{\mathbf{X}}$ & $\bar{x}$ & & & $\bar{X}$ & & $\bar{X}$ \\
\hline Master Oscillator Room & $\bar{X}$ & $\bar{X}$ & & & & & \\
\hline
\end{tabular}

\subsubsection{Interface to Ionizing Radiation Hazard Monitors}

The Integrated Safety System (ISS) shall provide an interface to the ionizing radiation monitors and respond to the ionizing radiation hazard by preventing access to unsafe areas. Note that the ISS does not directly monitor ionizing radiation levels but responds to signals generated by the monitors supplied by WBS 1.8.6.

\subsubsection{Hardware Interface to Building}

The Integrated Safety System (ISS) shall provide an interface to the building wiring to monitor doors and actuate door bolts and sensors supplied in the building wiring in WBS 1.2.2.

\subsubsection{FEP Software Requirement Specification}

The detailed requirements of the Integrated Safety System FEP shall be documented in a separate Software Requirements Specification. The SRS shall include functional requirements for FEP-resident user interfaces, data processing, alarm processing, data logging, trending, device drivers, embedded controller interfacing, or other special hardware requirements.

Note that the FEP is a monitor only. It does not accomplish safety functions. The FEP shall be built to NIF QA Level 3 as defined in the NIF Ancillary Software Quality Assurance Plan (ref. para. 2.6 this document).

The SRS shall also include performance or other dynamic requirements as well as other architectural requirements that may imply system partitioning. The FEP SRS shall describe functional requirements that are expected to be implemented by either the supervisory software or other collaborating FEPs.

All FEPs shall conform as much as possible to a common design for the implementation of functional requirements that are shared by more than one instance of an FEP.

\subsubsection{PLC Software Requirement Specification}

The detailed requirements of the Integrated Safety System Programmable Logic Controller (PLC) shall be documented in a separate Software Requirements Specification (SRS). The SRS shall include functional requirements for PLC resident logic, I/O tables, data processing, alarm processing, and other special requirements.

The PLC SRS shall describe system test requirements, and functional requirements expected to be implemented in other collaborating systems. 


\subsubsection{Lifetime, Replaceability and RAM}

\subsubsection{Lifetime}

Lifetime: The ISS shall be designed to operate for 30 years.

\subsubsection{Replaceability}

Any portion of the ISS which cannot reasonably be designed for 30 year lifetime shall be designed to be replaced or repaired at reasonable cost in a timely manner consistent with the overall availability of the System.

\subsubsection{Reliability}

The ISS shall have an overall reliability of $99.97 \%$. Reliability is defined as the probability of meeting the minimum requirements of the experiment per no-yield shot.

\subsubsection{Availability}

The ISS shall have a shot availability of at least $99.62 \%$. The ISS is unavailable when it is undergoing unplanned maintenance. Unplanned maintenance includes failure detection and active repair as well as logistic and administrative downtimes.

\subsubsection{Maintainability}

The ISS shall have a scheduled maintenance plan that fits within an overall annual plant goal of 69 days. The unplanned maintenance goal is 1.0 days per year. Opportunistic maintenance activities are performed between shots and during other system downtimes.

\subsubsection{Recovery From Abnormal Event}

The time required for the ISS to recover from any abnormal event shall be less than the maximum times cited below, as a function of the expected yearly frequency of occurrence of the event.

\begin{tabular}{cc} 
Expected Frequency of Occurrence Per Year. $F$ & Maximum Recovery Time \\
\hline $\mathrm{F} \geq 1$ & 24 hours \\
$1>\mathrm{F}>1 \mathrm{e}-2$ & 1 week \\
$1 \mathrm{e}-2>\mathrm{F} \geq 5 \mathrm{e}-4$ & 3 months
\end{tabular}

Probabilities listed in DOE-STD-1020-94 shall be used for natural phenomena.

For frequent events, the maximum allowed recovery time may be restricted by availability requirements to be less than that shown in the table above.

\subsubsection{Environmental/EMI Requirements}

\subsubsection{Environmental, Temperature/Humidity}

The ISS shall be capable of operating in the temperature and humidity previously specified for the laser and target area building. In general, the ISS components are capable of operating in a standard commercial temperature and humidity of $5^{\circ} \mathrm{C}$ to $40^{\circ} \mathrm{C}\left(41\right.$ to $\left.104^{\circ} \mathrm{F}\right)$ and $20 \%$ to $80 \% \mathrm{RH}$ non-condensing when installed in their appropriate enclosures.

\subsubsection{Environmental/Plenum Approved/CL2 Cables}

All ISS cabling installed in air plenums shall use plenum approved cabling. Otherwise control cabling shall conform to $\mathrm{CL} 2$ specifications.

\subsubsection{Environmental, EMI Requirements}

All ISS electronic equipment shall be designed or purchased to tolerate, where warranted, an operating environment of $50 \mathrm{~V} / \mathrm{m}$ external electrical field and $0.1 \mathrm{~A} / \mathrm{m}$ external magnetic field without adverse effects. (ref ANSI C95.1-1991). 


\subsubsection{Environmental, Ionizing Radiation}

Ionizing Radiation effects are an issue only inside the target room. Inside the target room careful consideration shall be given to the radiation and EMI effects as described in "Radiation and EMI Effects in the NIF Environment", UCRL-ID-118202.

\subsubsection{Optical Communication Safety}

Where the ISS uses lasers for optical communications, it shall conform to the applicable eye-hazard safety requirements to mitigate the possibility of eye exposure to an uncapped laser diode or unterminated active fiber source. Applicable standards include ANSI Z-136.1 (1993) and ANSI Z-136.2 (1988).

\subsubsection{Human Factors}

The ISS shall be designed in an ergonometric fashion to ensure that reliability during operation and maintenance is sustained at a level consistent with meeting overall availability and reliability objectives. Consistency in displays, warnings, and human interfaces should be maintained throughout the ISS and, if possible, throughout the NIF facility (i.e. GUI displays, access ports, tooling).

\subsubsection{Documentation and Records}

The ISS shall provide sufficient documentation to comply with the NIF Quality Assurance Plan, and DOE Order 5700.6C, Quality Assurance, Criterion-4 Documents and Records, which states: "Documents shall be prepared, reviewed, approved, issued, used and revised to proscribe processes, specify requirements or establish design. Records shall be specified, prepared, reviewed approved and maintained."

Examples of documents that should be controlled include drawings, data files, calculations, specifications, computer codes, purchase orders, vendor supplied documents, procedures, work records and data sheets and test records. Revisions should be reviewed by the organizations that originally prepared and approved the documents. Controlled documents should be distributed to those doing the work.

\subsection{Logistics}

\subsubsection{Spares .}

As a part of the design/construction project, the Integrated Safety System shall provide an initial complement of spare parts as required to activate the system.

\subsubsection{Maintenance}

As a part of the design/construction project, the Integrated Safety System shall provide all equipment required to inspect, service, and maintain all subsystems within the ISS to meet the maintainability and availability requirements. Maintenance equipment shall include all handling fixtures, lifting equipment, and other special tools not otherwise available within the NIF, that are necessary to perform any planned (scheduled or unscheduled) maintenance activity. 


\subsection{Revision Record}

Rev Date Change by Description

letter

A 12Mar96 Severyn

A 30May96 Severyn

2 07Aug96 Severyn

$2 \quad 20$ Aug96 Severyn

$\begin{array}{lll}2 & 03 \text { Sep96 } & \text { Clasen } \\ 2 & \text { 03Sep96 } & \text { Severyn }\end{array}$

Convert to FileMaker, update

Post Mid Title-1 update

para 2.6, update QA Plan reference

para 3.1.1, Add T-1 Abort System definition.

para 3.1.4, Add ref to T-1 Abort signal.

para 3.1.5, Add WBS 1.5.4.3, Abort System.

para 3.2.00, Add "The T-1 Abort System shall. .."

para 3.2.01, Change QA levels to 1996 standards

para 3.2.14, Change ref to FEP QA level

para 2.2, deleted refs to DOE 6430.1A and 5480.11.

Added ref. to 10 CFR 835 Occupational Radiation Protection.

(flowdown from FRPC and SDR4). Also added ref. to DOE QA

document (flowdown from FRPC and SDR4).

Convert to Word

Call rev B $=$ rev 2 for Sherpa consistency.

Deleted "Integrated Safety System" from the title of many paragraphs. i.e.

"Integrated Safety System, Functional Requirements" became simply

"Functional Requirements". 


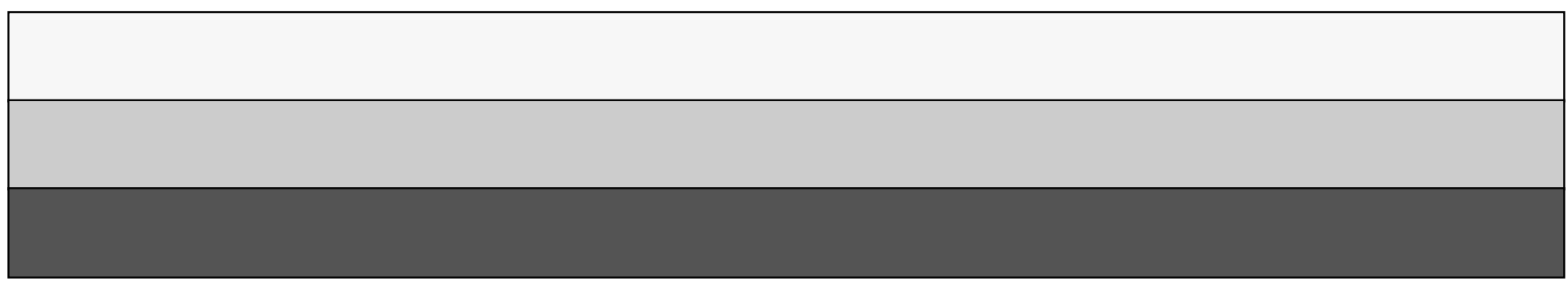

